Kansas State University Libraries

New Prairie Press

Conference on Applied Statistics in Agriculture

1989 - 1st Annual Conference Proceedings

\title{
KANSAS WHEAT OBJECTIVE YIELD SURVEY
}

Eldon J. Thiessen

Follow this and additional works at: https://newprairiepress.org/agstatconference

Part of the Agriculture Commons, and the Applied Statistics Commons

\section{(c) (i) $\Theta$}

This work is licensed under a Creative Commons Attribution-Noncommercial-No Derivative Works 4.0 License.

\section{Recommended Citation}

Thiessen, Eldon J. (1989). "KANSAS WHEAT OBJECTIVE YIELD SURVEY," Conference on Applied Statistics in Agriculture. https://doi.org/10.4148/2475-7772.1461

This is brought to you for free and open access by the Conferences at New Prairie Press. It has been accepted for inclusion in Conference on Applied Statistics in Agriculture by an authorized administrator of New Prairie Press. For more information, please contact cads@k-state.edu. 


\title{
RANSAS WHEAT OBJECTIVE YIELD SURVEY
}

\author{
by Eldon J. Thiessen, Deputy State Statistician \\ Ransas Agricultural Statistics \\ 444 S.E. Quincy \\ Topeka, Kansas 66683-3580
}

\section{ABSTRACT:}

In response to farmers, millers, and government needs, the USDA began research on objective measurements of wheat yields in 1938. USDA's current objective yield program providing monthly pre-harvest forecasts of wheat production beginning on May 1 now includes 18 states and accounted for 87 percent of the U.S. wheat production in 1988 .

The Wheat Objective Yield Survey is a systematic subsample of the March Agricultural Survey conducted by Kansas Agricultural Statistics as part of the Quarterly Agricultural Survey program of the National Agricultural Statistics Service (NASS). The fields and sample plots within the fields are selected following very carefully established rules. The counts and measurements from these sample fields are used in the forecast models developed by maturity category to predict number of heads and weight per head, the two components of yield which will provide the monthly yield indications.

Since the probability that a field will contain a sample is proportional to the expanded acres in the field, each acre has an equal chance of being selected for a sample and the average of the individual sample yields provides a self-weighting forecast of yield for the state.

KEYWORDS: Area Frame, Forecast Model, List Frame, Objective Yield, Sample Plot.

\section{INTRODUCTION}

USDA began research on pre-harvest wheat objective yield surveys in 1938. The demand for yield statistics came from farmers, millers, experiment stations, and other government agencies. They wanted more accurate forecasts of yield and quality per acre by variety and area during the growing season. The farmers needed the information to better plan their sales. The millers were requesting the data to help them locate the wheat varieties best suited for their milling needs. The only information available at that time concerning crop yields was based on USDA questionnaires distributed by mall to farmers and summarized at the State level. It was felt that more accurate locality information should be gathered to provide objective measurements of yield by area and seeded varieties within a state. The earliest studies were conducted in Kansas, Minnesota, Nebraska, North Dakota, Oklahoma, and South Dakota. In 1939, the study areas covered all of Kansas and North 
Dakota but only the important wheat producing areas of the other states. The field work in 1939 and 1940 was done by three crews of two men each. The men traveled in automobiles equipped with crop meters designed to measure frontage of wheat standing for harvest along a predetermined route that would provide adequate coverage for each state. The crews would stop at regular intervals and clip samples of wheat heads from 24 inch by 26.14 inch plots; approximately $1 / 10,000$ of an acre. Approximately 1,320 samples were taken in 1939 and 2,200 in 1940.

The laboratories which processed these harvested samples were located in Manhattan, Kansas and Fargo, North Dakota in cooperation with the Departments of Milling and Agronomy of Kansas State College and North Dakota Agricultural College. Kansas State College was very involved in those early projects, including building the small head threshers used to thresh the grain from the sampled plots.

From that early research has developed USDA's current Objective Yield program providing monthly pre-harvest forecasts of wheat production beginning on May 1. The monthly wheat production estimates are based on estimates of acres intended for harvest and average yields per acre. Both estimates are developed using indications from probability and nonprobability surveys. The wheat objective yield survey (a probability survey) and the Farm Report ( a non-probability survey) each provide indications for the two components of wheat production. The Wheat Objective Yield survey is the more scientific survey and now includes 18 states that accounted for 87 percent of the U.S. wheat production in 1988. The information in this presentation deals primarily with the procedures for the Wheat Objective Yield Survey and forecasting yields. The need for early data on wheat production is still important. Many improvements in survey procedures and yield models have been developed, increasing the reliability of the USDA's pre-harvest production forecasts. Dr. Arlin Feyerherm, here at Kansas State University, has been extensively involved in studying the USDA's Objective Yield program, including linking current USDA models with weather variables.

\section{SAMPLE DESIGN}

The early research into objective pre-harvest measurements of wheat yields utilized a route sampling technique rather than a random selection of wheat fields. This involved using a crop meter which measured the frontage of wheat along a predetermined sample route. Depending upon the density of wheat acreage in a county, samples were taken at intervals of 25 to 200 crop meter units on the right hand side of the road. One crop meter unit was equal to $1 / 50$ of a mile. The exact interval used was predetermined, based on the ratio of the preliminary office estimates of wheat acreage to total land area in the county. Two random numbers were preselected to be used in locating two plots from the selected field for harvesting. 
The sample for today's Objective Yield wheat surveys in Kansas are subsamples of the March Agricultural Survey conducted by Kansas Agricultural Statistics as part of the Quarterly Agricultural Survey program of the National Agricultural Statistics Service (NASS). The Quarterly Agricultural Survey (QAS) program utilizes a Multiple Frame survey design. NASS has, over the years, developed an extensive list of farm operators to be used for the agency's survey program. The list contains control information describing each operator's agricultural operation. This list is constantly being reviewed and updated with the most recent control information and current farm operators. For the QAS surveys the list is stratified based upon each farm operator's control information for Cropland, Grain Stock Capacity, and Hogs. Farm operators with more than three thousand hogs, or five hundred thousand bushels grain stocks capacity or six thousand acres of cropland are all selected for the survey. All other operators are sampled. Samples are replicated to provide about sixty percent overlap between each survey. Therefore, sixty percent of the respondents to the March Agricultural Survey would also have been part of the December Quarterly Survey .

Since no list is ever complete, NASS has also developed an Area Frame containing the entire land area in the State of Kansas. An area frame is developed by stratifying the land area of the State into different land-use strata which identify different levels of agricultural intensity. A random sample of land areas (called segments), generally one square mile in size, are then selected to represent the frame. In Kansas, we have 8 land-use strata and a sample of 435 segments. In June, each individual operating land within the 435 segments is interviewed concerning his farming operation, both inside and outside the segment. The July estimate of acres planted to fall harvested crops relies heavily upon the indications received from this Area Frame survey. The Quarterly Agricultural Survey program also uses the Area Frame to measure the incompleteness of the List Frame. This is accomplished by matching all operators found operating land within the segments on June 1 against the List Frame. Any Area Frame operator not found on the List Frame on June 1 is then identified as a non-overlap (NOL) operator and his operation, together with all other NOL operators, becomes a measure of the incompleteness of the List Frame. For the September, December, and March Quarterly Agriculture Surveys, a sample of these NOL operators is surveyed to measure the incompleteness of the List Frame for each survey. The Quarterly Agricultural Surveys then include all sampled list data and data from a sample of the NOL area operators to account for the total population.

Therefore, the sample of wheat farms utilized for the Wheat Objective Yield Survey will contain both List frame and (NOL) Area Frame operators. Only operators with wheat intended for harvest are selected to participate in the survey. The selection process involves several steps but can be described as follows: All List and Area Frame operators, along with the total acres of wheat they intend to harvest 
for grain, are arranged randomly by strata. A systematic sample of $X_{h}$ operators is selected using as an interval $W_{h} / X_{h}$ acres, where $W_{h}$ is the total acres of wheat reported for harvest by strata. The Wheat Objective Yield sample for Kansas is 275.

After the operators are selected for the survey, field interviewers will personally visit each farm operator and draw out on a grid all of his wheat fields intended for harvest. The fields for each operator which will be included in the survey are selected systematically following prescribed rules. Two sample plots or units consisting of 3 rows 21.6 inches long are carefully located within each selected field using a random number of paces along the edge of the field and into the field, starting at the first accessible corner when approaching the sample field. Each unit contains both count areas and clip areas. The same plots will be visited each month. A specially designed form is used by the interviewer during each visit to collect the counts by unit for each sample. The interviewer must identify the maturity category for each unit and determine the distance between rows. Then, depending on the maturity category, counts are made for number of stalks, number of heads in Late Boot, number of emerged heads, or number of detached heads. If the maturity category of the sample is Late Boot to Soft Dough, heads are clipped from designated clip areas and sent to the regional lab for count and weight measurements. When samples reach hard dough or ripe, all heads within the count areas are clipped and sent to the regional lab for final measurements. The data collected are not only used for current estimates, but also become part of the data base used for developing the historic models for following years.

\section{FORECAST MODELS}

To forecast yield per acre, a series of regression equations are used that forecast two components of yield for each sample. The two components are number of heads and weight per head. These two components are used to produce an estimate of bushels per acre for each sample. Since the probability that a field will get a wheat objective yield sample is proportional to the expanded acres in the field planted to that crop, every acre planted to wheat has an equal chance of being selected for a sample. The average of these individual sample yields then provide a self-weighting forecast of yield for the state. The forecast models used to estimate the number of heads and weight per head are based upon the maturity classification of the sample units.

The NASS survey procedures identify seven different maturity categories. The counts and measurements used to predict number of heads and weight per head for each category are as follows: 
Number of Heads

Pre-flag

Flag or Early Boot No. of Stalks

Late Boot or Flower Emerged Heads \& Heads in Late Boot

Milk

Soft Dough

Hard Dough

Ripe
Emerged Heads \& Heads in Late Boot

Emerged Heads \& Heads in Late Boot

Actual Count of all Heads

Actual Count of all Heads
Weight Per Head

1. Historical Avg.

2. Historical Avg.

1. Historical Avg.

2. Historical Avg.

1. Fertile Spikelets

2. Historical Avg.

1. Grains/Head

2. Weight/Head

1. Grains/Head

2. Weight/Head

Actual Weights of Threshed Grain

Actual Weights of

Threshed Grain

All of the counts used in the models relate to the randomly selected plots in the sample fields. One model is used for each category to predict the final number of heads at harvest for each sample. For samples in early Boot or lower maturity, the count of stalks in the sample plots is used to model final number of heads expected at harvest. Field counts of emerged heads and heads in Late Boot are used for samples in Late Boot through Soft Dough to model final number of heads expected. At maturity, the actual count of heads is used.

Two models are used to predict the final weight per head at harvest for each sample. The two models are weighted together using the $\mathrm{R}^{2}$ from the individual models to arrive at the predicted weight per head. For samples in Early Boot or earlier only historical average weights per head are used to predict final weights, since no field counts are available.

The count of fertile spikelets per head and historical averages are used for samples in Late Boot and Flower Maturity. From Milk to Soft Dough maturity, the counts of grains per head and weights per head are used to predict final weights. At maturity, the actual weight of harvested grain is used.

The models used to predict final number of heads and weight per head are developed using field counts and measurements from the five previous years. Statistical analysis is run to identify outliers and leverage points before equations are developed. 
The net yield (Yi) for each sample is determined by $\mathrm{Yi}=\mathrm{Fi} \cdot \mathrm{WI} \cdot \mathrm{C}$ Li, where the components of the gross yield $F i$ (number of heads) and Wi (weight per head) are estimated for each sample using current counts as described above. The models used are based on historical number of heads and weights per sample by maturity category. Estimates of harvest loss (Li) are based on a straight 5 year historical average until harvest begins. The conversion factor (C) uses the row space measurement from the plot to inflate the counts to a per acre basis. Tables 1 through 4 provide the forecast components used to estimate yields for the 1986 and 1988 Kansas Objective Yield Surveys. Each of the components of yield by maturity category and the State level are shown in these tables. The State level average is the straight average of all samples each month. The tables show that samples on May 1 are generally in maturity category Late Boot or earlier. Models for these maturity categories utilize historical averages almost exclusively for the weight per head models, and number of stalks to model number of heads.

By June 1, most samples are in the Late Boot to Soft Dough maturity categories. Models for these categories rely almost completely on current data to model both weight per head and number of heads. The weight per head models use counts of number of grains and weight per head to estimate final weight per head. The number of heads per sample are modeled using the counts of heads in Late Boot or higher maturity.

By July 1, nearly all samples are either in the Hard Dough or Mature category and are harvested and sent to the laboratory in Topeka. The models now use actual weights per head and number of heads to estimate the yield per acre.

The weight per head in 1986 steadily increased as the crop moved toward maturity. The exact opposite occurred in 1988 with the highest estimate of weight per head occurring on May 1, which was based exclusively on historical averages. Tables 1 and 3 clearly show that fairly significant changes in weight per head can occur as the crop matures. These changes are real and are based on many environmental factors such as moisture supplies, fertilizer, temperatures, and disease and insect problems being experienced by the crop.

Tables 2 and 4 show that the estimate of number of heads per sample changes very little after June 1. The May 1 estimate of number of heads is based on the number of stalks counted in the samples. This tends to represent a maximum number of heads that could reach maturity. In an optimum year, with ideal conditions, all stalks could produce a head. However, in drought years, or years with late freezes or with significant disease or insect problems, the May 1 estimate of number of heads could decline significantly as the crop matures. Generally, the estimate of number of heads per sample does not change much after June 1 . 
The final component of net yield is harvesting loss. The straight five year average is used for the May 1 and June 1 models. The July 1 model will use the actual harvest loss for samples that have been harvested by the farmer, but it is not until August that the actual harvest loss is used for all samples. This is generally the only survey component which will indicate a change from the July 1 indicated yield.

After a sample has been harvested, the interviewer will return to the operator for a post-harvest interview to obtain final acres harvested on his operation and the yield per acre of the sample field that has been used all season. This farmer's reported yield is another indication which is available beginning in July to help estimate yield.

Tables 5 and 6 summarize the yield components, indicated yields and USDA forecast yields for each monthly survey in 1986 and 1988 . It is important to recognize that USDA forecast yields are designed to reflect the current situation expecting normal conditions until harvest. As was noted earlier, other non-probability survey indications are also available but high priority is placed on the data from the objective Yield indications. As farmers harvest their WOY sample fields, data are gathered on actual yields for the sample fields. These data are included in the table as farmer reported yields.

The September Agricultural survey conducted in early september is designed to obtain final wheat yields. The final USDA estimate of yield will be based on careful analysis of all these final indications. The Objective Yield modeled yields are generally very close to this final estimate.

\section{SUMMARY}

The Wheat Objective Yield Survey is a very important part of the USDA wheat production forecasts issued monthly May through July around the loth of the month. Improvements in sampling, modeling, and quality control have produced more reliable results. A constant effort is necessary to insure that field and lab procedures are clearly understood and followed. Therefore, quality control is a very important part of the survey procedure.

There are still issues that must be addressed relative to the Wheat Objective Yield program. Automated labs may help assure accurate data for the models. Research is needed to better tailor models for unusual years such as we've had recently. Better early season indicators are needed, as can be seen in reviewing the modeled results for May 1. 
1986 FORECAST COMPONENTS

Table 1 for weight per head

\begin{tabular}{l|rr|rr|rr|rr}
\hline Category & \multicolumn{2}{|c|}{ May 1} & \multicolumn{2}{|c|}{ June 1} & \multicolumn{2}{c|}{ July 1} & \multicolumn{2}{c}{ Final } \\
\hline & Num. & Avg. & Num. & Avg. & Num. & Avg. & Num. & Avg. \\
& Sample & Grams & Sample & Grams & Sample & Grams & Sample & Grams \\
\cline { 2 - 9 } Pre-Flag & 62 & .577 & 1 & .577 & & & & \\
Early Boot & 56 & .577 & 2 & .577 & & & & \\
Late Boot\& Flower & 14 & .577 & 54 & .577 & 1 & .585 & 1 & .585 \\
Milk & & & 111 & .614 & 2 & .644 & 2 & .644 \\
Soft Dough & & & 83 & .575 & 6 & .582 & 5 & .583 \\
Hard Dough & & & 2 & .533 & 48 & .617 & .48 & .608 \\
Mature & & & & & 195 & .640 & 196 & .644 \\
State & 132 & .577 & 253 & .592 & 252 & .634 & 252 & .635 \\
\hline
\end{tabular}

Tabie 2

1986 FORECAST COMPONENTS

\begin{tabular}{|c|c|c|c|c|c|c|c|c|}
\hline Category & \multicolumn{2}{|c|}{ May 1} & \multicolumn{2}{|c|}{ June 1} & \multicolumn{2}{|c|}{ July 1} & \multicolumn{2}{|c|}{ Final } \\
\hline & $\begin{array}{l}\text { Num. } \\
\text { Sample }\end{array}$ & $\begin{array}{l}\text { Avg. } \\
\text { Heads }\end{array}$ & $\begin{array}{c}\text { Num. } \\
\text { Sample }\end{array}$ & $\begin{array}{l}\text { Avg. } \\
\text { Heads }\end{array}$ & $\begin{array}{c}\text { Num. } \\
\text { Sample }\end{array}$ & $\begin{array}{l}\text { Avg. } \\
\text { Heads }\end{array}$ & $\begin{array}{c}\text { Num. } \\
\text { Sample }\end{array}$ & $\begin{array}{r}\text { Avg. } \\
\text { Heads }\end{array}$ \\
\hline $\begin{array}{l}\text { re-Flag } \\
\text { arly Boot }\end{array}$ & $\begin{array}{l}62 \\
56\end{array}$ & $\begin{array}{l}303 \\
351\end{array}$ & $\begin{array}{l}1 \\
2\end{array}$ & $\begin{array}{l}248 \\
254\end{array}$ & & & & \\
\hline $\begin{array}{l}\text { Late Boot \& Flower } \\
\text { Milk }\end{array}$ & 14 & 261 & $\begin{array}{r}54 \\
111\end{array}$ & $\begin{array}{l}302 \\
319\end{array}$ & $\begin{array}{l}1 \\
2\end{array}$ & $\begin{array}{l}297 \\
419\end{array}$ & $\begin{array}{l}1 \\
2\end{array}$ & $\begin{array}{l}297 \\
419\end{array}$ \\
\hline oft Dough & & & 83 & 293 & 6 & 270 & 5 & 278 \\
\hline Hard Dough & & & 2 & 276 & 48 & 297 & 48 & 297 \\
\hline ature & & & & & 195 & 307 & 196 & 306 \\
\hline Eate & 132 & 319 & 253 & 306 & 252 & 305 & 252 & 305 \\
\hline
\end{tabular}

Table 3

1988 FORECAST COMPONENTS

for weight per head

\begin{tabular}{|c|c|c|c|c|c|c|c|c|}
\hline Category & & & Jun & & $\mathrm{JuI}$ & 1 & & hal \\
\hline & $\begin{array}{l}\text { Num. } \\
\text { Sample }\end{array}$ & $\begin{array}{l}\text { Avg. } \\
\text { Grams }\end{array}$ & $\begin{array}{l}\text { Num. } \\
\text { Sample }\end{array}$ & $\begin{array}{l}\text { Avg. } \\
\text { Grams }\end{array}$ & $\begin{array}{c}\text { Num. } \\
\text { Sample }\end{array}$ & $\begin{array}{l}\text { Avg. } \\
\text { Grams }\end{array}$ & $\begin{array}{l}\text { Num. } \\
\text { Sample }\end{array}$ & $\begin{array}{l}\text { Avg. } \\
\text { Grams }\end{array}$ \\
\hline Pre-Flag & 95 & .603 & 1 & .592 & & & & \\
\hline $\begin{array}{l}\text { Early Boot } \\
\text { Late Boot \& Flower }\end{array}$ & 18 & .603 & $\begin{array}{r}1 \\
88\end{array}$ & $\begin{array}{l}.573 \\
.595\end{array}$ & & & & \\
\hline Milk & & & 103 & .581 & 1 & .572 & 1 & .572 \\
\hline Soft Dough & & & 48 & .498 & 4 & .557 & 1 & .496 \\
\hline Hard Dough & & & 0 & & 27 & .515 & 28 & .517 \\
\hline Mature & & & 0 & & 202 & .488 & 204 & .488 \\
\hline State & 113 & .603 & 241 & .569 & 234 & .491 & 234 & .489 \\
\hline
\end{tabular}

1988 FORECAST COMPONENTS

Table 4

for number of heads/sample

\begin{tabular}{|c|c|c|c|c|c|c|c|c|}
\hline \multirow[t]{2}{*}{ Category } & \multicolumn{2}{|c|}{ May 1} & \multicolumn{2}{|c|}{ June 1} & \multicolumn{2}{|c|}{ July 1} & \multicolumn{2}{|c|}{ Final } \\
\hline & $\begin{array}{c}\text { Num. } \\
\text { Sample }\end{array}$ & $\begin{array}{r}\text { Avg. } \\
\text { Heads }\end{array}$ & $\begin{array}{c}\text { Num. } \\
\text { Sample }\end{array}$ & $\begin{array}{r}\text { Avg } \\
\text { Heads }\end{array}$ & $\begin{array}{c}\text { Num. } \\
\text { Sample }\end{array}$ & $\begin{array}{r}\text { Avg. } \\
\text { Heads }\end{array}$ & $\begin{array}{c}\text { Num. } \\
\text { Sample }\end{array}$ & $\begin{array}{r}\text { Avg. } \\
\text { Heads }\end{array}$ \\
\hline Pre-Flag & 95 & 414 & 1 & 595 & & & & \\
\hline Early Boot & 18 & 514 & $\begin{array}{r}1 \\
88\end{array}$ & $\begin{array}{l}286 \\
369\end{array}$ & & & & \\
\hline $\begin{array}{l}\text { Late Boot \& Flower } \\
\text { Milk. }\end{array}$ & & & $\begin{array}{r}88 \\
103\end{array}$ & $\begin{array}{l}369 \\
416\end{array}$ & 1 & 468 & 1 & 468 \\
\hline Soft Dough & & & 48 & 382 & 4 & 378 & 1 & 412 \\
\hline Hard Dough & & & 0 & & 27 & 384 & 28 & 389 \\
\hline Mature & & & 0 & & 202 & 403 & 204 & 402 \\
\hline State & 113 & 437 & 241 & 396 & 234 & 404 & 234 & 405 \\
\hline
\end{tabular}


1986

YIELD COMPONENTS

Table 5

\begin{tabular}{|c|c|c|c|c|}
\hline May 1 & July 1 & Final & & \\
\hline Weight/Head (grams) & .577 & .592 & .634 & .635 \\
\hline of Heads/Sample & 319 & 306 & 305 & 305 \\
\hline $\begin{array}{l}\text { Harvesting Loss } \\
\text { (Bu./Acre) }\end{array}$ & 1.86 & 1.86 & 1.53 & 1.49 \\
\hline $\begin{array}{l}\text { Indicated Yields (WOY) } \\
\text { (Bu./Acre) }\end{array}$ & & & & \\
\hline Modeled & 31.9 & 31.1 & $\begin{array}{l}33.6 \\
33.3\end{array}$ & $\begin{array}{l}33.8 \\
33.6\end{array}$ \\
\hline $\begin{array}{l}\text { Farmer Reported } \\
\text { Sept. Ag. Survey }\end{array}$ & -- & -- & $\begin{array}{c}33.3 \\
--\end{array}$ & \\
\hline Season Yields & 33.0 & 32.0 & 32.0 & 33.0 \\
\hline
\end{tabular}

(Bu./Acre)

Table 6

YIELD COMPONENTS

\begin{tabular}{|c|c|c|c|c|}
\hline & May 1 & June 1 & July 1 & Final \\
\hline Weight/Head (Grams) & .603 & .569 & .491 & .489 \\
\hline of Heads/Sample & 437 & 396 & 404 & 405 \\
\hline $\begin{array}{l}\text { Harvesting Loss } \\
\text { (Bu./Acre) }\end{array}$ & 1.60 & 1.60 & .68 & .92 \\
\hline $\begin{array}{l}\text { Indicated Yields (WOY) } \\
\text { (Bu./Acre) }\end{array}$ & & & & \\
\hline $\begin{array}{l}\text { Modeled } \\
\text { Farmer Reported } \\
\text { Sept. Ag. Survey }\end{array}$ & $\begin{array}{c}46.3 \\
--\end{array}$ & 40.2 & $\begin{array}{l}36.3 \\
35.2\end{array}$ & $\begin{array}{l}33.8 \\
33.8 \\
33.7\end{array}$ \\
\hline $\begin{array}{l}\text { Season Yields } \\
\text { (Bu./Acre) }\end{array}$ & 38.0 & 35.0 & 35.0 & 34.0 \\
\hline
\end{tabular}




\section{REFERENCES}

Bond, Douglas. "Non-Sampling Errors from Lab Procedures of the wheat Objective Yield Survey", U.S. Department of Agriculture, Statistical Reporting Service Staff Report No. AGES841218, January 1985.

Gleason, Chap. "A Comparison of Alternative Winter Wheat Objective Yield Unit Sizes", U.S. Department of Agriculture, Statistical Reporting Service Staff Report, September 1973.

Fecso, Ron; Francisco, Carol; Fuller, Wayne. "An Assessment of Crop Production Estimates used with the Objective Yield Surveys", U.S. Department of Agriculture, National Agricultural Statistics Service, Staff Report No. YRB-85-05, August 1986.

King, Arnold; Jebe, Emil. "An Experiment in Preharvest Sampling of Wheat Fields", U.S. Department of Agriculture, Agricultural Marketing Service, August 1940.

King, Arnold; McCarty, Dale; McPeels, Miles. "An Objective Method of Sampling Wheat Fields to Estimate Production and Quality of Wheat", U.S. Department of Agriculture, Agricultural Marketing Service, February 1942.

Matthews, Vince. "Head Count Difference Between Sample Plots in the 1983-1985 Wheat Objective Yield Survey", U.S. Department of Agriculture, National Agricultural Statistics Service, Staff Report No. YRB-86-09, September 1986 .

National Agricultural Statistics Service. Objective Yield Survey and Editing Manual, U.S. Department of Agriculture, National Agricultural Statistics Service, 1988.

National Agricultural Statistics Service. Wheat Objective Yield Enumerator's Manual, U.S. Department of Agriculture, National Agricultural Statistics Service, 1988.

Vogel, Fred. "Crop Forecasting Methodology, Current and Future Procedures in the U.S.", U.S. Department of Agriculture, National Agricultural Statistics Service, August 1985. 